\title{
Multi-scale reinforcements stimulated dynamic recrystallization and mechanical behavior of as-extruded titanium matrix composites
}

\author{
Peikun Qiu ${ }^{a}$, Yuanfei Han ${ }^{a *}$, Guangfa Huang ${ }^{a}$, Jianwen Le ${ }^{a}$, Lihua Duc ${ }^{c}$, Weijie Lu ${ }^{a, b^{*}}$ \\ ${ }^{a}$ State Key Laboratory of Metal Matrix Composites, School of Materials Science and Engineering, Shanghai Jiao Tong University, Shanghai 200240, China \\ ${ }^{b}$ Shanghai Key Laboratory of Advanced High Temperature Materials and Precision Forming, \\ Shanghai 200240, China
}

${ }^{c}$ AVIC Manufacturing Technology Institute, Beijing 100024, China

\begin{abstract}
Different volume fraction of $\mathrm{TiB}, \mathrm{TiC}$ and $\mathrm{La}_{2} \mathrm{O}_{3}$ multiple-reinforced Ti6Al4V composites were fabricated by casting and followed by forging and hot extrusion. The microstructural evolution and mechanical behavior of $\left(\mathrm{TiB}+\mathrm{TiC}+\mathrm{La}_{2} \mathrm{O}_{3}\right) / \mathrm{Ti} 6 \mathrm{Al} / \mathrm{V}$ composites during hot extrusion were investigated. The microstructural observations showed that the $\mathrm{TiB}_{\mathrm{w}}$ and $\mathrm{TiC}_{\mathrm{p}}$ agglomeration disappeared and distributed more homogeneously in the Ti matrix after hot extrusion. Besides, TiB $\mathrm{w}$ exhibited highly preferred alignment along the extrusion direction and $\mathrm{TiC}_{\mathrm{p}}$ distributed along the same direction. Besides, two kinds of microstructure bands with distinctive spatial distributions of reinforcements were formed after hot extrusion: equiaxial bands embedded with fairly substantial reinforcements and finer basket-weave bands containing few reinforcements, in which the micron-scale $\mathrm{TiB}_{\mathrm{w}}, \mathrm{TiC}_{\mathrm{p}}$ and submicron-scale $\mathrm{La}_{2} \mathrm{O}_{3}$ particle stimulating nucleation occurred and resulting dynamic recrystallization were the main mechanisms responsible for grain refinement. The tensile tests revealed that hot extrusion significantly increased elongation of $\left(\mathrm{TiB}^{\mathrm{T}} \mathrm{TiC}+\mathrm{La} \mathrm{O}_{3}\right) / \mathrm{Ti} 6 \mathrm{Al} 4 \mathrm{~V}$ composites from $2.71 \%$ to $13.2 \%$ accompanied by slightly decreasing ultimate tensile strength from 954MPa to 903MPa, compared with that of the as-forged composites, which due to a complex process of reinforcements/matrix interaction during extrusion and dynamic recrystallization.
\end{abstract}

Key words: Hot extrusion, Multi-scale, Titanium matrix composites, dynamic recrystallization

* Corresponding author.

Email address: hyuf1@sjtu.edu.cn (Yuanfei Han), luweijie@sjtu.edu.cn (Weijie Lu).

\section{Introduction}

Titanium matrix composites(TMCs) with preeminent properties such as high specific strength, high specific stiffness, outstanding oxidation and corrosion resistance, and admiring elevated temperature durability have been considered as potential materials for extending application on aerospace and advanced weapon systems ${ }^{[1-3]}$. In recent years, discontinuously reinforced titanium matrix composites (DRTMCs), particularly fabricated by in situ method, have been paid considerable attention due to the cost-effectiveness and feasibility in producing composites with low interface contamination and better compatibility between the matrix and reinforcements compared to ex situ fabrication techniques ${ }^{[4-5]}$. Ceramic particles such as TiB2, TiB, TiC and SiC have been regarded as effective reinforcements inTMCs, among which TiB and TiC have attracted great interest because of their excellent thermodynamic stability and similar density and chemical compatibility to titanium. Additionally, rare earth elements including La, Y, Nb, Er, Gd and Ce, are added and deoxidize the titanium alloys, by which rare earth oxide was synthesized and enhances the mechanical properties and thermal stability of TMCs ${ }^{[6-9]}$.

So far, numerous effects have been carried out to investigate the effect of traditional metal pressure processing on TMCs, such as forging, rolling, and extrusion, which reveal that the composites reinforced with oriented arrangement of fibers exhibit higher strength compared to those with random arrangement ${ }^{[10-13]}$. Among the (C) The Authors, published by EDP Sciences. This is an open access article distributed under the terms of the Creative Commons Attribution License 4.0 (http://creativecommons.org/licenses/by/4.0/). 
traditional processing technique, hot extrusion provided more promising application due to high efficiency for fibers realignment and expected strengthening effect. Meanwhile, extrusion evidently refined grains of matrix, leading to higher strength and better ductility. Additionally, several investigations indicate that DRTMCs with low volume fraction of reinforcements have more superior comprehensive mechanical properties by virtue of better deformation coordination between reinforcements and matrix ${ }^{[14-15]}$. Nevertheless, few research have been conducted to investigate the effect of hot extrusion on the microstructure and mechanical properties of DRTMCs with low volume fraction of reinforcements, especially for that of multiple-reinforced TMCs.

In the present work, low volume fraction of $\mathrm{TiB}, \mathrm{TiC}$ and $\mathrm{La}_{2} \mathrm{O}_{3}$ multiple-reinforced Ti6Al4V matrix composites were fabricated and processed by forging and hot extrusion. The effect of microstructure and reinforcements evolution on the mechanical properties of the composites after extrusion is to be investigated. Besides, the mechanisms of reinforcements stimulated dynamic recrystallization behavior will be discussed.

\section{Material and experiments}

2.1 Preparation and processing of the TMCS

$\left(\mathrm{TiB}+\mathrm{TiC}+\mathrm{La}_{2} \mathrm{O}_{3}\right) / \mathrm{Ti} 6 \mathrm{Al} 4 \mathrm{~V}$ composites with different volume fraction of reinforcements were in situ fabricated by consumable vacuum arc remelting (VAR) furnace using common casting technique. In the preparation of composites, commercial sponge titanium ( $99.9 \%$ purity), AIV alloy, pure Al ( $99.99 \%$ purity), LaB6 powder ( 99 purity), and B4C powder (98\% purity) were taken as raw materials and the theoretical volume fraction of reinforcements are list in Table 1.

Table 1 The volume fraction of in situ synthesized $\mathrm{TiB}, \mathrm{TiC}$ and $\mathrm{La}_{2} \mathrm{O}_{3}$ in the as-fabricated composites

\begin{tabular}{lllll}
\hline \multirow{2}{*}{ Samples } & \multicolumn{4}{l}{ Reirforcements (vol. \%) } \\
\cline { 2 - 5 } & TiB & TiC & $\mathrm{La}_{2} \mathrm{O}_{3}$ & Total \\
TMC1 & 0.79 & 0.09 & 0.12 & 1.00 \\
$\mathrm{TMC2}$ & 1.19 & 0.19 & 0.12 & 1.50 \\
$\mathrm{TMC} 3$ & 1.60 & 0.28 & 0.12 & 2.00 \\
\hline
\end{tabular}

The proportional raw materials were mixed firstly, and pressed into preformed bars on press machine followed. The preformed bars were welded into longer ones as the electrode in VAR furnace. During the melting process, the chemical reaction among LaB6, B4C and Ti occurred as followed:

In order to obtain cast ingots with high chemical homogeneity, the composites were melted three times.

After melting, the cast ingots were machined and polished into forging ingots with smooth surface. The ingots were heated to $1473 \mathrm{~K}$ and hold for $30 \mathrm{~min}$ before forging, and the forging process was carried out on hydraulic press machine with maximum $3000 \mathrm{kN}$ press. Subsequently, the forging billets were machined into cylinder shape with $85 \mathrm{~mm}$ diameter and $50 \mathrm{~mm}$ height as extrusion billets. Finally, the as-forged composites billets were extruded with an extrusion ratio of 7:1 at $1253 \mathrm{~K}$, after which rods of diameter $30 \mathrm{~mm}$ were obtained.

\subsection{Characterization}

The phase identification of the as-forged composites was analyzed on an X-ray diffraction equipment (D/max 2550 V, Rigaku) using CuKa radiation. Morphology observation were performed on an optical microscope (MEF4A/M, Leica), and a field emission scanning electron microscope (NOVA NanoSEM 230, FEI). Samples for OM and SEM observation were cut from the as-forged and as-extruded composites, and prepared by mechanical grinding, polishing and etching using Kroll's solution ( $5 \mathrm{ml} \mathrm{HF}+10$ $\mathrm{ml} \mathrm{HNO} 3+85 \mathrm{ml} \mathrm{H} 2 \mathrm{O})$

Tensile specimens with dog-bone shape, gauge section size of $4 \mathrm{~mm}$ in width, $2 \mathrm{~mm}$ in thickness and $15 \mathrm{~mm}$ in length, were machined from the as-forged pieces along the forging direction and the as-extruded rods along the extrusion direction. Tensile test was conducted on a universal testing machine (Roell Z020, Zwick) at an initial strain 
rate of $10^{-3} / \mathrm{s}$. The tensile test was repeated in triplicate and average values of the measurements were presented for each sample.

\section{$\underline{\text { 3. Results }}$}

3.1 Phase identification

Fig.1 shows the X-ray diffraction patterns of the as-forged 1.0 vol.\%, 1.5 vol.\% and 2.0 vol.\% $\left(\mathrm{TiB}+\mathrm{TiC}+\mathrm{La}_{2} \mathrm{O}_{3}\right) / \mathrm{Ti} 6 \mathrm{Al} 4 \mathrm{~V}$ composites. The results confirmed that TiB, TiC and $\mathrm{La}_{2} \mathrm{O}_{3}$ were in situ synthesized in the composites, and no obvious diffraction peaks of $\mathrm{B} 4 \mathrm{C}$ and LaB6 were detected, which indicated that $\mathrm{B} 4 \mathrm{C}$ and LaB6 reacted completely with Ti during melting.

Fig. 2 shows the microstructure of the as-forged and as-extruded composites. It can be seen from Fig. 2 a), b), c) that the composites in as-forged were characteristic of multiple colonies of a laths. TiB presented obvious fiber shape, and TiC was particle shape. Both the TiB and TiC distributed randomly in titanium matrix.

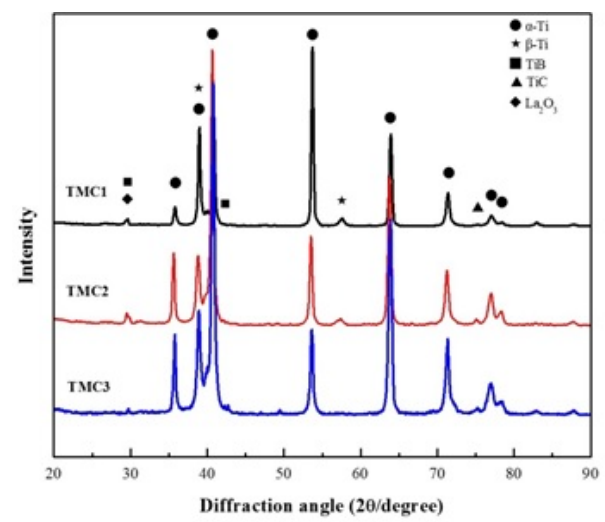

Fig.1 XRD pattern of the as-forged TMC1, TMC2 and TMC3

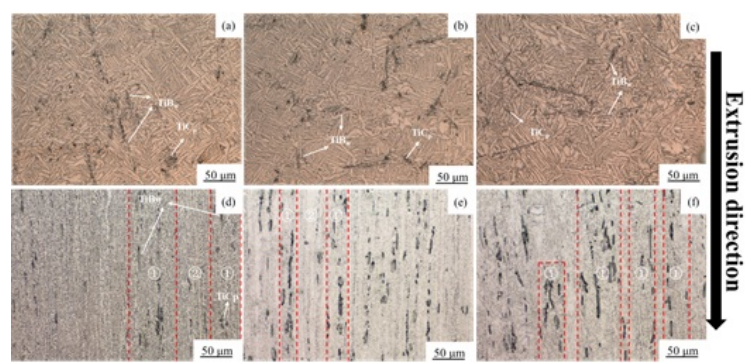

Fig.2 OM micrograph of (a) (b) $1.0 \mathrm{vol} \%$, (c) (d) $1.5 \mathrm{vol} \%$ and (e) (f) $2.0 \mathrm{vol} \%$ (TiB $+\mathrm{TiC}+\mathrm{La}_{2} \mathrm{O}_{3}$ )/Ti6Al4V composites before and after extrusion, where (1) and (2) denotes equiaxial and basket-weave microstructure zone, respectively

3.2 Microstructure evolution and redistribution of reinforcements during extrusion

The microstructure displayed remarkable difference after extrusion compared to the as-forged ones. Fig. $3 \mathrm{~d}$ ), e), f) indicated that the as-extruded composites tended to present two kinds of microstructure bands, namely equiaxial bands and basket-weave bands. In the basket-weave bands, the lamellar size was finer than that of the asforged ones, and in the other parts, the coarse basket-weave microstructure transformed into fine equiaxial one. Moreover, more reinforcements were apt to embedded into the equiaxial microstructure, while few reinforcements appeared in the basket-weave bands. That is to say, the reinforcements-rich regions were more likely to form equiaxial bands during extrusion.

Furthermore, it was found that TiB fibers were broken into shorter segments, lead to decrease of their aspect ratio, and only few TiC particles were divided into smaller ones, as showed in Fig.4. Additionally, several microvoids appeared at the fracture end of TiB fibers after extrusion, which hardly occurred before extrusion. 


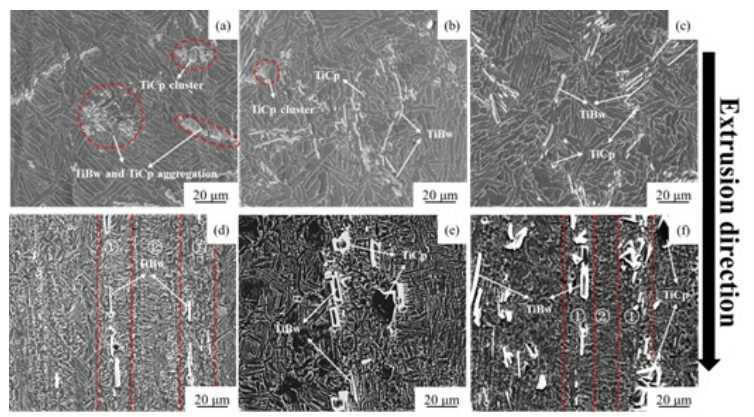

Fig.3 SEM micrograph of (a) (b) 1.0 vol\%, (c) (d) 1.5 vol\% and (e) (f) 2.0 vol\% (TiB + TiC + La2O3)/Ti6Al4V composites before and after extrusion, where (1) and (2) denotes equiaxial and basket-weave microstructure zone, respectively

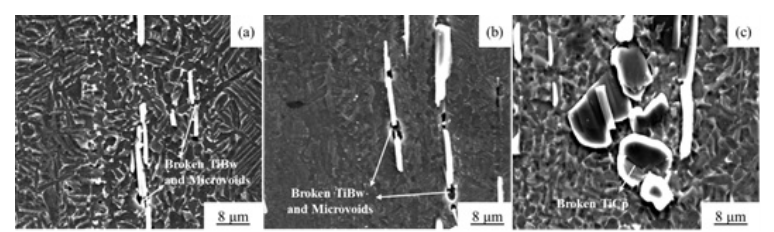

Fig.4 SEM micrograph of the as-extruded (a) $1.0 \mathrm{vol} \%$, (b) $1.5 \mathrm{vol} \%$, (c) $2.0 \mathrm{vol} \%$ (TiB + TiC + La2O3)/Ti6Al4V composites

3.3 Mechanical properties of the composites

In order to investigate the effect of extrusion on the as-fabricated TMCs, the room temperature tensile properties of composites before and after extrusion were measured. As presented in Fig.4, the yield strength and ultimate strength displayed the same response for the composites reinforced with different volumes fraction of TiB, $\mathrm{TiC}$ and $\mathrm{La}_{2} \mathrm{O}_{3}$ after extrusion, only slight decrease occurred. Particularly, the ultimate strength decrease only 75MPa for TMC3. Besides, with the increasing of volume fraction of reinforcements, the ultimate strength of the as-extruded composites decreased. Nevertheless, the ductility of the as-extruded composites were much superior to that of the as-forged ones. As showed in Fig.4, the elongation of TMC1 enhanced twice after extrusion, from 3.55\% to $14.2 \%$. For TMC2 and TMC3, approximately fourfold and more than twice improvement have been achieved, from $2.71 \%$ to $13.2 \%, 4.6 \%$ to $14.3 \%$, respectively. The slight reduction of strength and substantial improvement of elongation can be attributed to the break of reinforcements and matrix microstructure transformation, which will be discussed in the following.

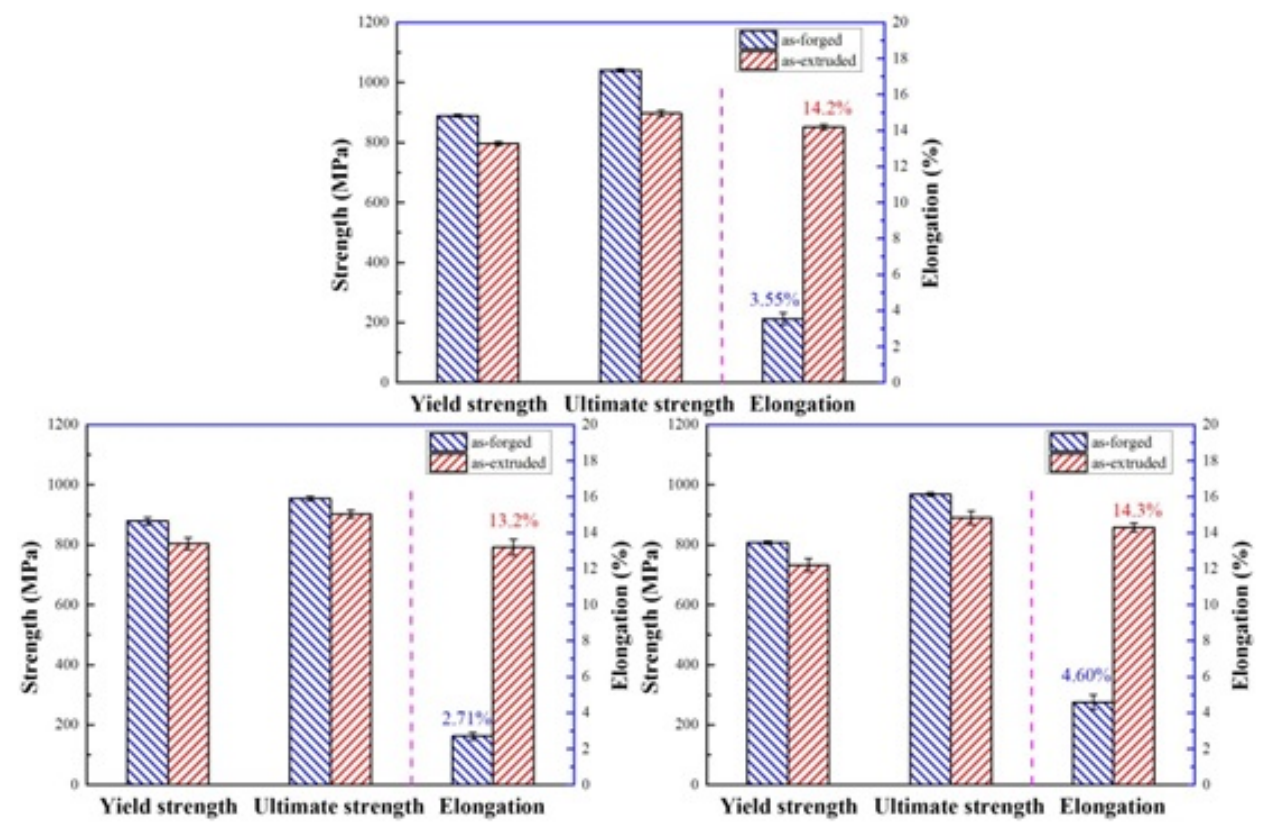

Fig.5 Tensile properties of (a) 1.0 vol.\%, (b) 1.5 vol.\%, (c) 2.0 vol.\% (TiB + TiC + La2O3)/Ti6Al4V composites before and after extrusion. 


\section{Discussion}

4.1 Effect of microstructure evolution on the mechanical properties of the composites after extrusion

Generally, titanium alloys with basket-weave microstructure manifested higher strength than that with equiaxial one. As showed in the results, the microstructure of the composites transformed from full basket-weave microstructure to mixture of equiaxial microstructure bands and finer basket-weave bands after extrusion. Additionally, according to a great deal of research results $[2,10,13,16]$, oriented distributed of TiB fibers should have remarkably increased the strength of TMC. In present investigation, although TiB fibers aligned along the extrusion direction, TiB long fibers fractured into shorter ones accompanied with microvoids emerging. It is universally known that materials were subjected to triaxial compressive stress and the inner metal flowed with the plastic flow line along the extrusion direction, the TiB long fibers would be acted upon by bending stress, resulting in the fracture of TiB fibers, and reducing the strengthening effect. Combining these two contradictory factors, the strength of composites after extrusion fell slightly compared to the as-forged composites. In term of the as-extruded composites, with the increase of volume fraction of reinforcements, the average aspect ratio of TiB reduced to 12.0, 7.8 and 5.1, respectively. Especially, the aspect ratio of several TiB fibers was down to less than 2.7 , which was the critical aspect ratio for TiB to play a strengthening role in $\mathrm{TMCs}^{[13]}$. Consequently, the ultimate strength moderately decreased as volume fraction of reinforcements enhanced.

With respect to the significant improvement of ductility, microstructure refinement and homogeneous distribution of reinforcements after extrusion were the main reasons. On the one hand, the reinforcements-rich regions in the as-extruded composites transformed to fine equiaxial microstructure due to dynamic recrystallization and the thickness of a lath in reinforcements-lean regions decreased. On the other hand, a great amount of TiB fibers and TiC aggregated locally, leading to premature fracture of composites and dramatically damage to ductility. As composites were subject to hot extrusion, the reinforcements clusters ameliorated.

\subsection{Mechanisms of reinforcements stimulated dynamic recrystallization}

For titanium matrix, a phase is HCP structure, which is short of effective dislocation slip system. As a result, the mismatch between hard ceramic phase TiB or TiC and titanium matrix occurred and resulted in strong stress concentration in the regions near reinforcements during hot extrusion, which caused high dislocation density there. According to the study of Humhpherys and Doherty ${ }^{[17-18]}$, particles smaller than $1 \mu \mathrm{m}$ would prevent or retard recrystallization due to their pinning effect on grain boundary in aluminum matrix composites. In contrast, particles larger than $1 \mu \mathrm{m}$ could promote dynamic recrystallization. As shown in Fig.6, submicron La $\mathrm{O}_{3}$ particles were synthesized closed to TiB fibers, and located at triple grain boundary. A great number of DRX grains and high dislocation density were observed near TiB fibers. Moreover, the submicron La2O3 particles tended to pin grain boundary sliding, which was benefit to hind the growth of grains and refine the microstructure. Combined the results in Fig.3, the interaction of reinforcements may also play an important role in dynamic recrystallization. Koken et al. ${ }^{[19]}$ found that particle clusters had much more influence on recrystallization rather than simply on the particle size due to more stored energy for recrystallization nucleation.
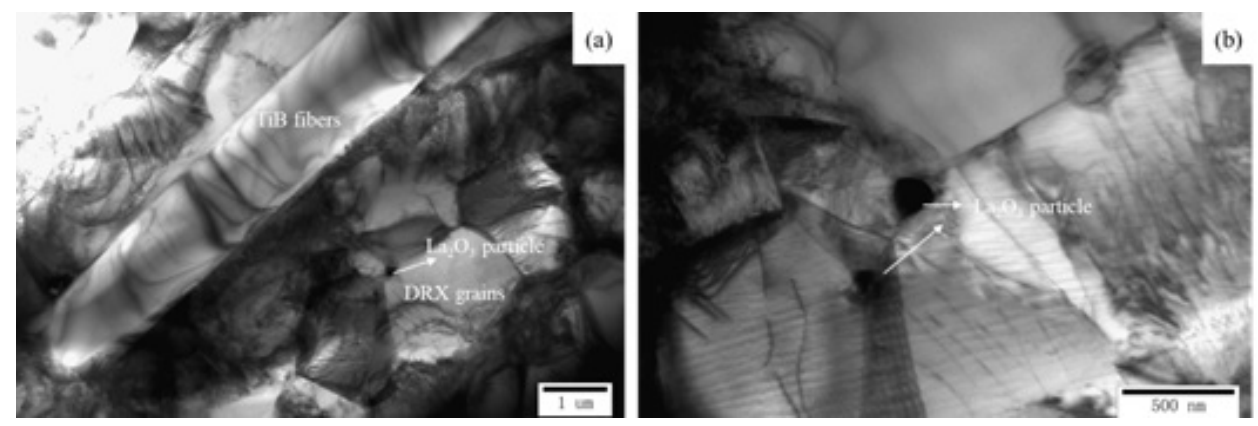

Fig.6 TEM microstructure of the 1.5 vol.\% extruded (TiB + TiC + La2O3)/Ti6Al4V composites after extrusion.

\section{Conclusion}


The influence of hot extrusion on the microstructure and mechanical properties of $\left(\mathrm{TiB}+\mathrm{TiC}+\mathrm{La}_{2} \mathrm{O}_{3}\right)$ multiple-scale reinforced Ti6Al4V matrix composites were investigated. The main conclusions were listed as followed:

1. Reinforcements stimulated dynamic recrystallization was found in the as-extruded composites. Equiaxial microstructure bands in reinforcements-rich regions and finer basket-weave microstructure bands in reinforcements-lean regions were discovered after hot extrusion.

2. Hot extrusion remarkably improved the elongation of the as-fabricated composites accompanied by slight decrease of strength, among which the elongation of 1.5 vol\% $\left(\mathrm{TiB}+\mathrm{TiC}+\mathrm{La}_{2} \mathrm{O}_{3}\right)$ increase by nearly four times compared to that of as-forged composites.

3. The mismatch between larger TiB or TiC or clusters and titanium matrix provided more stored energy to stimulated dynamic recrystallization and the submicron $\mathrm{La}_{2} \mathrm{O}_{3}$ particles acted as obstacles to grain boundary and hinder the growth of DRX grains.

\section{Acknowledgements}

This work is financially supported by the National Natural Science Foundation of China ( Grant NO. )

\section{$\underline{\text { 7. References }}$}

[1] S.C. Tjong, Y.W. Mai, Compos. Sci. Technol. 68 (2008) 583-601.

[2] D. Xu, W.J. Lu, Z.F. Yang, et al, J. Alloy. Compd.400 (2005) 216-221.

[3] Z.G. Zhang, J.N. Qin, Z.W. Zhang, Y.F. Chen, W.J. Lu, D. Zhang, Mater. Lett. 64 (2010) 361-363.

[4] Y.F. Han, J.X. Li, G.F. Huang, Y.T. Lv, X. Shao, W.J. Lu, D. Zhang, Mater. Des. 75 (2015) 113-119.

[5] Y. Yu, W.C. Zhang, W.Q. Dong, J.L. Yang, Y.J. Feng, Mater. Sci. Eng. A 638 (2015) 38-45.

[6] W.J. Lu, X. Zhang, R. Wu, H. Sakata, H. Mori, Scr. Mater 44 (2001) 2449-2455

[7] L. Xiao, W.J. Lu, J.N. Qin, Y.F. Chen, D. Zhang, M.M. Wang, Compos. Sci. Technol. 69 (2009) 1925-1931.

[8] Z.F. Yang, W.J. Lu, J.N. Qin, J.J. Gu, D. Zhang, J.L. Liu, J. Alloys Compd. 425 (2006) 379-383.

[9] K. Geng, W.J. Lu, Z.F. Yang, D. Zhang, Mater. Lett. 57 (2004) 4054-4057.

[10] F.C. Ma, W.J. Lu, J.N. Qin, Mater. Des. 28 (2007) 1339-1342.

[11] H.A. Rastegari, S. Asgari, S.M. Abbasi, Mater. Des. 10 (2011) 5010-5014.

[12] L.J. Huang, L. Geng, B. Wang, H.Y. Xu, B. Kaveendran, Compos. Part A 43 (2012) 486-491.

[13] X.L. Guo, L.Q. Wang, M.M. Wang, J.N. Qin, D. Zhang, W.J. Lu, Acta Mater. 60 (2012) 2656-2667.

[14] S.Y. Sun, M.M. Wang, L.Q. Wang, J.N. Qin, W.J. Lu, D. Zhang, Compos. Part B 43 (2012) 3334-3337.

[15] L.J. Huang, S. Wang, L. Geng, B. Kaveendran, H.X. Peng, Compos. Sci. Technol. 82 (2013) 23-28.

[16] G.F. Huang, X.L. Guo, Y.F. Han, L.Q. Wang, W.J. Lu, D. Zhang, Mater. Sci. Eng. A 667 (2016) 317-325. 
[17] F.J. Humphreys, P.N. Kalu, Acta Metall. 12 (1987) 2815-2829.

[18] R.D. Doherty, D.A. Hughes, F.J. Humphreys, J.J. Jonas, D.J. Jensen, M.E. Kassner, W.E. King, T.R. McNelley, H.J. McQueen, A.D. Rollett, Mater. Sci. Eng. A 238 (1997) 219274.

[19] E. Koken, N. Chandrasekaran, J.D. Embury, G. Burger, Mater. Sci. Eng. A 104 (1988) 163-168. 